\title{
Noise Exposure and Hearing Threshold Profile among Zumba Fitness Regulars in Kuantan, Pahang, Malaysia.
}

\author{
Razali A, Othman MS, Rahman MS, Misaridin NFI \\ Department of ORL-HNS, Kulliyyah of Medicine, International Islamic University Malaysia (IIUM).
}

\section{ABSTRACT}

INTRODUCTION: Recreational noise exposure has become a major threat to the hearing system, and this includes exposure to loud noise during group exercises such as Zumba Fitness, where loud music plays an important role. This study aimed to assess the noise exposure and hearing threshold profile among Zumba Fitness regulars in Kuantan, Malaysia. MATERIALS AND METHODS: Noise exposure and hearing profile threshold were measured during Zumba Fitness sessions at a fitness studio in Kuantan, Malaysia from $24^{\text {th }}$ June 2014 to $12^{\text {th }}$ August 2014. Noise exposure was measured using a noise dosimeter for one hour of Zumba Fitness session with a total of nine sessions run by three different instructors while sound level pressure was taken using a sound level meter during ambient, peak session and during cooling down. Thirty participants answered questionnaires and underwent pure tone diagnostic audiometry test at a local clinic for hearing threshold documentation. RESULTS: Some areas of the hall posed higher risks of causing noise-induced hearing loss especially near the amplifiers. There were periods when the hearing level exceeded $115 \mathrm{dBA}$. Early abnormal pattern could be observed in the hearing profiles of some of the participants to suggest preliminary hearing problems. CONCLUSION: Zumba Fitness regulars have a risk of developing noise-induced hearing loss and preventive steps should be properly addressed as NIHL is permanent and irreversible.

KEYWORDS: Zumba fitness, hearing loss, recreational noise, pure tone audiometry, noise-induced hearing loss.

\section{INTRODUCTION}

Hazardous exposures to loud noise can come from a myriad of sources, often times from inconspicuous locations and activities such as the hustle and bustle of traffic to the leisure enjoyment of music. ${ }^{1}$ Prolonged exposure of excessive noise of or exceeding $85 \mathrm{dBA}$ could cause noise-induced hearing loss $(\mathrm{NIHL}){ }^{2}$ Occupational noise exposure is a major cause of NIHL and has been on a rising trend in Malaysia from 2008 to 2014, based on a report by Social Organization Security (SOCSO). ${ }^{3}$ NIHL however, has also been reported from non-occupational origin, and recreational noise has been strongly implicated. ${ }^{4}$ This exposure ranges widely from the popular usage of personal listening devices ${ }^{5}$ to loud noise exposure in discotheques. ${ }^{6}$ Continuous

Corresponding Author:

Assoc. Prof. Dr. A. Razali

Department of ORL-HNS,

Kulliyyah of Medicine,

International Islamic University Malaysia (IIUM).

Jalan Sultan Ahmad Shah, Bandar Indera Mahkota,

25200 Kuantan, Pahang, Malaysia

Tel: +609-5704450

Email: ailin@iium.edu.my exposure to loud music exceeding $85 \mathrm{dBA}$ could cause pathophysiological changes to the auditory system that could lead to hearing impairment. ${ }^{7}$ This study seeked to examine this latest exercise trend that could be a source of hazardous noise exposure. Zumba Fitness is a form of group exercise using upbeat loud music andt is popular not just in Malaysia but around the world. It combines Latin American music and dances with aerobics steps and movement. Recent study has reported that Zumba Fitness has significant effect on body composition of women especially their body weight, fat percentage and fat mass. ${ }^{8}$ Literature review on noise exposures during Zumba fitness programme is noticeably scarce at the time this manuscript was written. This study aims to explore the noise exposure andhearing threshold profile among Zumba Fitness regulars in Kuantan, Pahang, Malaysia and hopes that this study would trigger more awareness on the dangers of noiseinduced hearing loss so that appropriate preventive steps could be implemented. 


\section{MATERIALS AND METHODS}

\section{Study Location}

This study was conducted at a local fitness studio in Kuantan, Pahang from $24^{\text {th }}$ June 2014 to $12^{\text {th }}$ August 2014. The fitness studio is located on level 2, Try My Gym. The premise is fully air-conditioned, and there are two speakers (a) placed next to each other at the right side of the hall. The studio could accommodate about 40 people comfortably at any particular time and the class sessions are conducted and managed by three licensed Zumba instructors and a manager.

The floor of the fitness studio is made of wooden plank and the front wall (b) is covered with mirrors. A fitting room $(h)$ is located at the back left-hand side of the studio. The height of the studio is 2.984 meter with the length (c) of 20.539 meter. The back

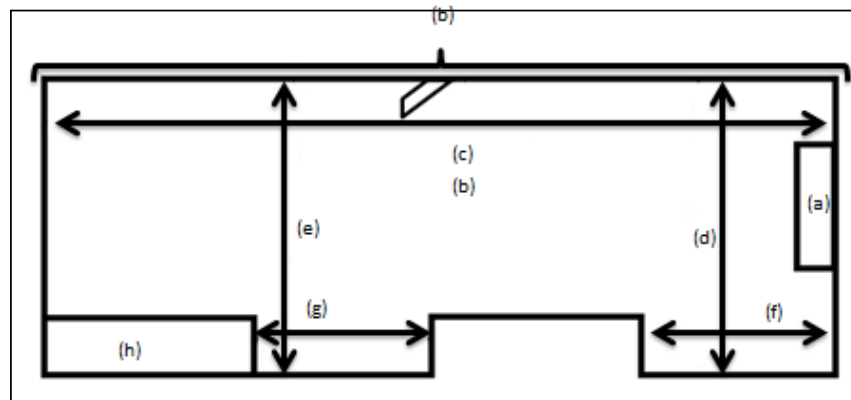

Figure 1: Sketch of the studio from above view. It provides 2 amplifiers at (a) and mirrors (b) which cover the front wall. Fitting room (h) is located at the back, left side of the studio.

\section{Study population}

Two issues are investigated in this study; the noise exposure during Zumba Fitness sessions and hearing profile of the Zumba Fitness regulars. For the first part, the studio was divided into five different areas with the amplifier as the referred point. The aerial sketch for the noise exposure study is as follow (Figure 2):

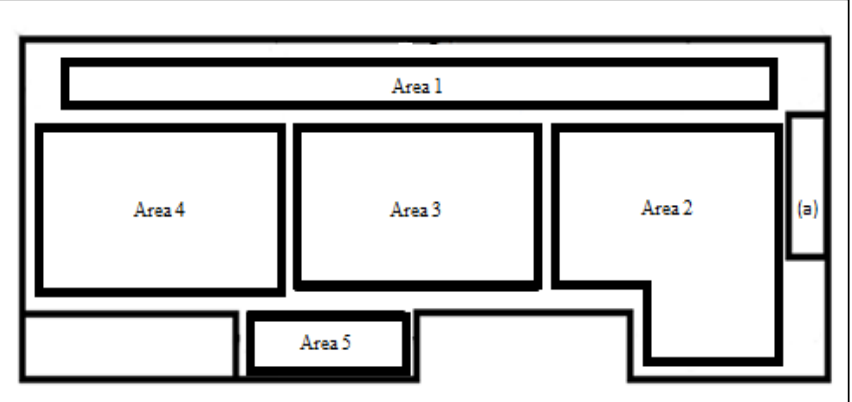

Figure 2: The aerial sketch of the studio which have been divided into Instructor's (1), Nearest (2), Middle (3), Furthest (4) and Between the Wall (5) wall has 2 extended compartments; the one nearest to the speakers (I) measured 6.551 meters $\times 1.22$ meters while the other compartment (II) measured 4.2069 meters $\times 2.202$ meters. The aerial sketch of the studio is as follows (Figure 1 ):

\section{Noise Exposure}

The three instructors running the Zumba Fitness classes; Instructor A, B and C each takes turn to run 9 classes a week. Noise exposure was recorded in nine different sessions, three sessions for each instructor. In each session, five volunteers were selected and placed at five different areas as mentioned above. A QuestPro Edge4 personal noise dosimeter was attached on each volunteer's right shoulder and the microphone placed as near to the ear level as possible. It measures the noise exposure for a Zumba Fitness session (about one hour) and the results were extracted using ProQuest2. Sound pressure level was also taken on three different occassions in all five areas; at ambient, peak session and during cooling down. All readings were measured using sound level meter. Among the parameters collected were noise dosage, Time Weighted Average (TWA), Equivalent Continuous Sound Pressure Level (Leq) and Upper Limit time when the noise reaches beyond $115 \mathrm{~dB}$ (UL115). All data were analyzed by SPSS 19.0.

\section{Hearing Profile}

Convenient sampling strategy was used for the study where only those who answered the questionnaires and agreed to do the Pure Tone Audiometry (PTA) test are taken as test subjects. Prior to the test, a written consent was obtained to ensure subjects' confidentiality and anonymity. The questionnaires comprised of contact information for PTA assessment, personal data and questions to identify any ear and hearing problems. The exclusion criteria included existing ear or hearing problems. The remaining respondents were called for PTA assessment to assess the ear and hearing threshold at $0.5,1,2,3,4,6$, and $8 \mathrm{kHz}$ for both ears. A total of 47 women answered the questionnaires, but only 30 participants undergone PTA assessment. Reasons for their exclusion included not consenting for PTA assessment $(n=7)$, no respond for appointment $(n=6)$, not available for PTA assessment session $(n=2)$, and active ear diseases $(n=2)$. The participants' data on socio-demographic, Zumba activities, symptoms of having ear problems and all risk factors of hearing loss were analyzed using SPSS 19.0. 
The volunteers were seen and examined at a local Ear and Hearing Clinic. Upon determining that they have not been exposed to loud noise 14 hours prior to the appointment we proceeded to perform diagnostic pure tone audiometry (GSI61) conducted in a sound-proof room using head-phone (TDH49P) and bone-conductor (RadiogearB71W).

\section{RESULTS}

\section{Part One: Noise Exposure}

From the personal dosimeter, we documented the noise exposure in different areas of the fitness studio conducted by the three different instructors. Subsequently, we compared specific areas in the studio and also classes run by the three different instructors.

Table 1 showed the average reading of dosimeter for five different areas in three different instructors' classes. For Instructor A, areas 1 and 3 are the two areas that were at risk. The mean dose for both areas were $78.6 \%$ and $49.5 \%$ respectively. The mean TWA for both areas were also above the permissible limit which were $88.8 \mathrm{dBA}$ and $86.3 \mathrm{dBA}$ respectively. Additionally, the mean Leq were also excessive with 97.4 dBA for Area 1 and 94.9dBA for Area 3. All the areas in Instructor A's class recorded at least 1 second of exceeding the upper limit time except for Area 5; with Area 1 recording exposure of more than 30s. For instructor $B$, the only area at risk was Area 1 with the mean TWA of $86.3 \mathrm{dBA}$ and mean Leq of $94.7 \mathrm{dBA}$.

Additionally, except for the Area 4 and 5, other areas had at least 1 second recorded duration exceeding the upper limit time. Meanwhile, for instructor C, Area 2 was the only area that had a reading where the mean Leq exceeded the $94 \mathrm{dBA}$ limit. No upper limit time was recorded during her class.

Table 1: Average of three dosimeter readings conducted by three different Zumba instructors (A, B and C).

\begin{tabular}{|c|c|c|c|c|}
\hline \multirow{2}{*}{ Session** } & \multicolumn{4}{|l|}{ Parameters } \\
\hline & $\begin{array}{l}\text { Mean Dose } \pm \text { S.D. } \\
(\%)\end{array}$ & $\begin{array}{l}\text { Mean TWA } \pm \text { S.D. } \\
(\mathrm{dBA})\end{array}$ & $\begin{array}{l}\text { Mean Leq } \pm \text { S.D. } \\
(\mathrm{dBA})\end{array}$ & $\begin{array}{l}\text { Upper Limit } \\
\text { Time (sec)* }\end{array}$ \\
\hline \multicolumn{5}{|l|}{ A } \\
\hline Area 1 & $78.6 \pm 25.8$ & $88.8 \pm 1.5$ & $97.4 \pm 1.3$ & 30 \\
\hline Area 2 & $21.1 \pm 4.0$ & $83.2 \pm 0.9$ & $91.9 \pm 1.1$ & 1 \\
\hline Area 3 & $49.5 \pm 46.3$ & $86.3 \pm 3.2$ & $94.9 \pm 3.4$ & 3 \\
\hline Area 4 & $7.9 \pm 0.9$ & $82.6 \pm 6.4$ & $91.6 \pm 6.3$ & 1 \\
\hline Area 5 & $8.1 \pm 1.7$ & $80.0 \pm 1.0$ & $87.9 \pm 0.8$ & 0 \\
\hline \multicolumn{5}{|l|}{ B } \\
\hline Area 1 & $48.1 \pm 26.8$ & $86.3 \pm 2.8$ & $94.7 \pm 2.6$ & 4 \\
\hline Area 2 & $28.6 \pm 10.9$ & $84.3 \pm 1.6$ & $92.7 \pm 1.4$ & 1 \\
\hline Area 3 & $21.1 \pm 8.1$ & $83.0 \pm 1.6$ & $91.5 \pm 1.4$ & 1 \\
\hline Area 4 & $9.4 \pm 4.2$ & $79.4 \pm 1.9$ & $87.9 \pm 2.4$ & 0 \\
\hline Area 5 & $6.9 \pm 1.5$ & $78.3 \pm 0.9$ & $86.8 \pm 0.9$ & 0 \\
\hline \multicolumn{5}{|l|}{$C$} \\
\hline Area 1 & $17.1 \pm 3.9$ & $82.4 \pm 0.9$ & $91.3 \pm 1.1$ & 0 \\
\hline Area 2 & $22.8 \pm 3.4$ & $83.5 \pm 0.7$ & $94.2 \pm 2.4$ & 0 \\
\hline Area 3 & $13.1 \pm 3.1$ & $80.9 \pm 1.4$ & $89.8 \pm 1.4$ & 0 \\
\hline Area 4 & $6.2 \pm 0.5$ & $77.7 \pm 0.3$ & $86.6 \pm 0.5$ & 0 \\
\hline Area 5 & $7.6 \pm 2.2$ & $78.7 \pm 1.2$ & $87.6 \pm 1.3$ & 0 \\
\hline
\end{tabular}

*total time recorded when the noise reaches beyond $115 \mathrm{dBA}$

${ }^{* *}$ Area 1 (Instructor), Area 2 (Nearest), Area 3 (Middle), Area 4 (Furthest) and Area 5 (Between the walls) 
Table 2 showed the average reading for all the five areas in the Zumba session. Generally, Area 1 was the most hazardous area. The mean dose was almost $50 \%$ with mean TWA of $85.8 \mathrm{dBA}$ and $94.4 \mathrm{dBA}$ for the mean Leq. There was also an average of 2 seconds exposure to the noise above 115dBA. Area 2 had the second highest reading with about $25 \%$ of dose, 83.7dBA of TWA and 93.1 dBA for Leq followed by Area 3, Area 5 and Area 4.

\begin{tabular}{lllll}
\hline \multicolumn{5}{c}{ Parameters Mean \pm S.D. } \\
\cline { 2 - 5 } Position*** & $\begin{array}{l}\text { Mean Dose } \pm \text { S.D. } \\
(\%)\end{array}$ & $\begin{array}{l}\text { Mean TWA } \pm \text { S.D. } \\
(\mathrm{dBA})\end{array}$ & $\begin{array}{l}\text { Mean Leq } \pm \text { S.D. } \\
(\mathrm{dBA})\end{array}$ & $\begin{array}{c}\text { Upper Limit } \\
\text { Time }(\mathrm{sec})^{* *}\end{array}$ \\
\hline Area 1 & $48.0 \pm 32.9$ & $85.8 \pm 3.2$ & $94.4 \pm 3.1$ & $2 \pm 7.0^{*}$ \\
Area 2 & $24.2 \pm 7.0$ & $83.7 \pm 1.1$ & $93.0 \pm 1.9$ & $0 \pm 1.0^{*}$ \\
Area 3 & $17.4 \pm 14.6$ & $83.4 \pm 3.1$ & $92.1 \pm 3.0$ & $0 \pm 1.0^{*}$ \\
Area 4 & $7.8 \pm 2.6$ & $78.4 \pm 2.7$ & $87.2 \pm 11.8^{*}$ & $0 \pm 0.0$ \\
Area 5 & $7.5 \pm 1.8$ & $78.7 \pm 1.0$ & $87.4 \pm 1.1$ & $0 \pm 0.0$ \\
p-value & $<0.001$ & $<0.001$ & $<0.001$ & $<0.02$ \\
\hline
\end{tabular}

*in Median (IQR)

**total time taken when the noise reach beyond $115 \mathrm{~dB}$

*** Area 1 (Instructor), Area 2 (Nearest), Area 3 (Middle), Area 4 (Furthest) and Area 5 (Between the walls)

Table 3 showed the mean results for each instructor's classes. Class A was the noisiest among all three classes followed by class $B$ and $C$ with the mean dose of about 20\% while the mean TWA and Leq almost reaching the maximum limit; $84 \mathrm{dBA}$ and
92.7 dBA respectively. Although the mean TWA of all classes did not exceed the upper limit, the result was significant with a $p$-value of less than 0.05 . Only class $A$ had an average of 1 second recorded for exposure to a noise of more than $115 \mathrm{dBA}$.

Table 3: Dosimeter readings of noise exposure conducted by the three instructors.

\begin{tabular}{lllll}
\hline \multicolumn{5}{l}{ Parameters Mean \pm S.D. } \\
\cline { 2 - 5 } Class & $\begin{array}{l}\text { Mean Dose } \pm \text { S.D. } \\
(\%)\end{array}$ & $\begin{array}{l}\text { Mean TWA } \pm \text { S.D. } \\
(\mathrm{dBA})\end{array}$ & $\begin{array}{l}\text { Mean Leq } \pm \text { S.D. } \\
(\mathrm{dBA})\end{array}$ & $\begin{array}{l}\text { Upper Limit Time } \\
(\mathrm{sec})^{* *}\end{array}$ \\
\hline A & $17.5 \pm 42.6$ & $84.0 \pm 4.5$ & $92.7 \pm 4.4$ & $1 \pm 1.0$ \\
B & $17.5 \pm 23.2$ & $82.3 \pm 3.5$ & $90.7 \pm 3.4$ & $0 \pm 1.0$ \\
C & $13.5 \pm 6.9$ & $80.6 \pm 2.4$ & $89.9 \pm 3.1$ & $0 \pm 0.0$ \\
$p$-value & 0.08 & $<0.05$ & 0.10 & 0.06 \\
\hline
\end{tabular}

\section{Part Two : Hearing Profile}

Socio-demographic distribution of all participants was collected via a questionnaire. In terms of age, majority of them (47\%) were between 21 to 30 years old. $30 \%$ were between 31 to 40 years old and only $23 \%$ were between 41 to 50 years old.

To investigate the women's noise exposures during Zumba with their hearing profile, their position during Zumba class must also be taken into consideration. Most of them stood in the middle (46 $\%)$ of the studio, followed by furthest from the speaker (30\%), between wall (17\%) and only $7 \%$ at nearest to the speaker area. This is crucial to determine the position of those who has the highest risk exposure to the noise.

Confounding factors to developing hearing loss were investigated among the participants of this study 
which includes the usage of earphone daily, frequent caffeine intake, history of allergic rhinitis, and family history of hearing problem. None of the participant reported the presence of noise exposure in their workplace.

Only 2 frequencies $(500 \mathrm{~Hz}$ and $8000 \mathrm{~Hz})$ of the average hearing levels of the right ear exceeded $20 \mathrm{dBHL}$. The rest of the hearing threshold is considered normal ( $20 \mathrm{dBHL}$ and below). The average hearing levels of all the participants also showed no configuration of noise notch at $3000 \mathrm{~Hz}$ to $6000 \mathrm{~Hz}$. For the left ear, all the frequencies were normal (20dBHL and lower) and no noise notch was observed.

We also compared the average PTA results between two different age groups, less than 40 years old and above 40 years old. The younger sample population has normal hearing levels which were between $5 \mathrm{~dB}$ to $15 \mathrm{~dB}$ for both ears. Portentiously, there was a change observed for the older sample group from
$3000 \mathrm{~Hz}$ onwards where the audiogram configuration deteriorated towards $8000 \mathrm{~Hz}$. The same pattern was observed on the left ear for both age groups where the younger group had a base line of $5 \mathrm{dBHL}$ and the older group had a higher base line hearing level of 20 $\mathrm{dBHL}$.

Figure 3 showed the average PTA result based on the participants' preferred position based on the four different areas in the studio. There was almost a similar pattern of hearing level for both right and left ear. For the right ear, the average reading for all positions was within the normal range except for the nearest (red line) to the speaker position where there was a marked deterioration in hearing threshold from $4000 \mathrm{~Hz}$ toward $8000 \mathrm{~Hz}$ which reached $40 \mathrm{dBHL}$. For the left ear, the decrease was not as steep as the right although it still exceeded the normal range, that is $25 \mathrm{dBHL}$. Participants preferring all the other positions were within the normal range of hearing which is $0-25 \mathrm{dBHL}$.

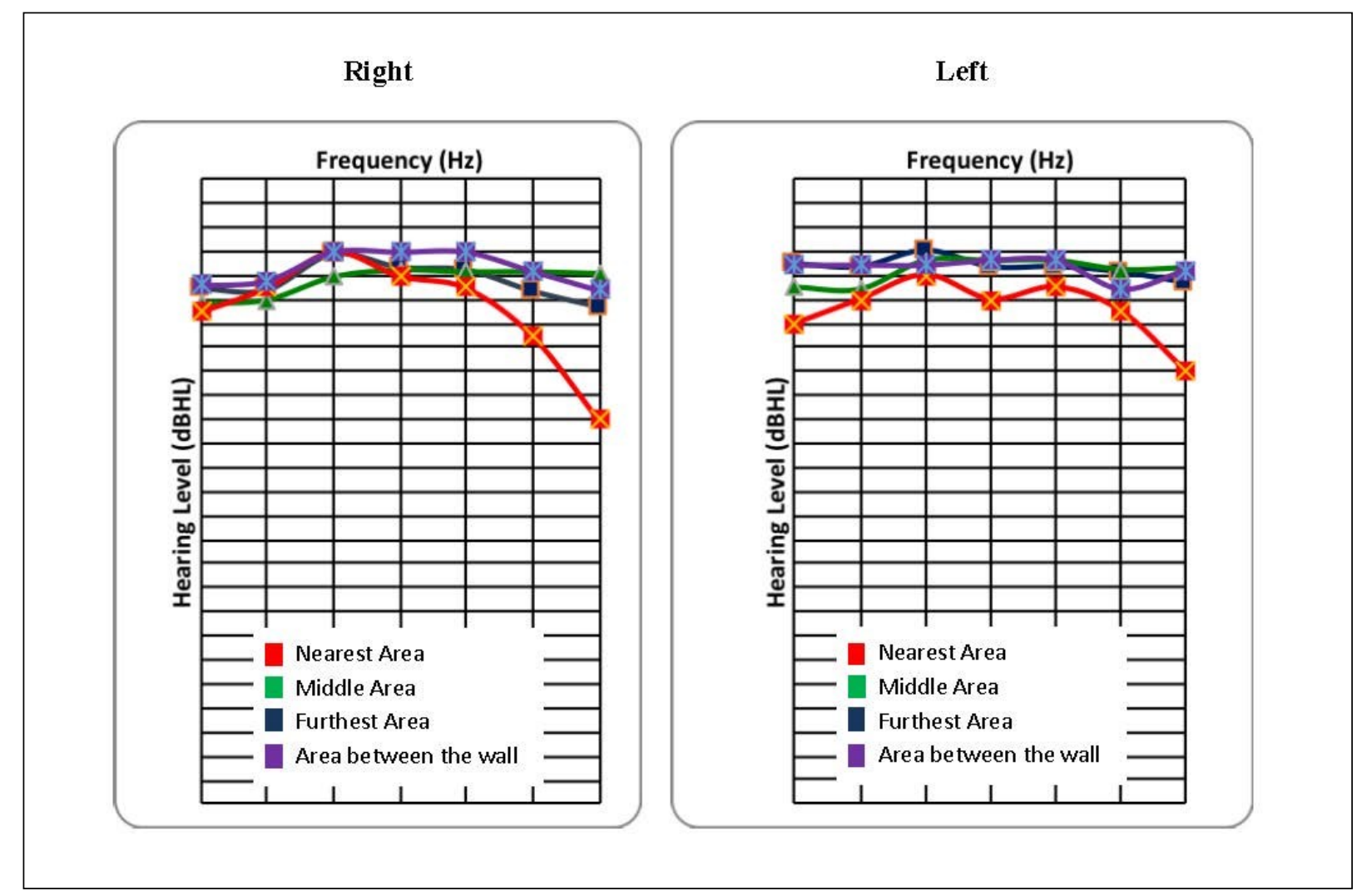

Figure 3: Average PTA result based on four different positions 


\section{DISCUSSION}

Our results showed that the mean total weighted average (TWA) for the instructor area (area 1) and area 2 (nearest area) were within the permissible limit which were $88.8 \pm 1.5 \mathrm{dBA}$ and $83.2 \pm 0.9 \mathrm{dBA}$ for instructor $A, 86.3 \pm 2.8$ and $84.3 \pm 1.6 \mathrm{dBA}$ for instructor $\mathrm{B}$, and $82.4 \pm 0.9 \mathrm{dBA}$ and $83.5 \pm 0.7 \mathrm{dBA}$ for instructor $C$. Based on the Factories and Machinery (Noise Exposure) Regulations 1989, ${ }^{11}$ the maximal exposure time allowed for noise exposure at $90 \mathrm{~dB}$ (A) is 8 hours per day. These two areas were considered at risk as the noise would come from the two amplifiers nearby and from the shouting of the instructors in front. This indoor noise exposure has similar findings with a study in a discotheque in Netherlands that found frequent visitors tend to stand closest to the loudspeakers, thus exposing themselves to the highest risk of hazardous noise level. ${ }^{6}$ In Korea, similar situation was revealed in karaoke rooms which also posed a threat to the hearing due to the existence of loudspeakers within a small room. ${ }^{12}$ In these three scenarios, music plays a crucial element and the louder the music, the more excitement and entertainment it generates. With the usual maximum output of a speaker having the capability to scale up to 100 to $120 \mathrm{dBA},,^{13}$ it is recommended that a safety limit of noise level should be implemented in enclosed, indoor areas where activities such as Zumba Fitness is held. This could markedly reduce the risk of noise-induced hearing loss while still allowing the participants to enjoy the health benefits from this fitness activity.

Not surprisingly, the elder group of Zumba Fitness regulars (more than 40 years old) presented with worse hearing thresholds especially on the high frequencies from $3000 \mathrm{~Hz}$ to $8000 \mathrm{~Hz}$. This similar pattern was also observed among steel band musicians aged 40 years and above who had prolonged exposure to loud music. ${ }^{14}$ In our study, the noise exposure were highest amongst Zumba Fitness regulars who placed themselves at the nearest area to the speakers (Area 2). The hearing threshold deterioration was very prominently seen on the right ear, documented at $40 \mathrm{dBHL}$. The right ear was severely affected due to the position of the women in area 2 in which the amplifier was located on the right side of their ear. The audiogram for the older group and those in area 2 did not show high frequency 'notch' typically observed in noiseinduced hearing loss patients, hence there is a need to rule out concurrent presbycusis. ${ }^{15}$ Thus, it could not be concluded that noise during Zumba per se contributed to their hearing problem as ageing might also be the cause of their hearing threshold deterioration. Other risk factors should be considered as well such as the daily usage of earphone and family history of hearing loss among others.

Nevertheless, imposing a safe sound level during Zumba Fitness session should really be implemented, because unlike any other music avenues such as discotheques that has to take into consideration their customer's satisfaction in experiencing music, ${ }^{16}$ Zumba Fitness class with safe sound level would not hamper the whole exercise activity where health benefit from the exercising is the priority. Additionally, protective hearing device such as earplugs and earmuffs should be encouraged as an additional noise control strategy. ${ }^{1}$ This is an important preventive measure as a study in America has reported that all the participants interviewed did not use hearing protection during dance and aerobic activities. ${ }^{17}$ This showed that the awareness of the hearing protection during noisy activities is still inadequate and more campaigns should target these groups to increase awareness against noiseinduced hearing loss.

\section{CONCLUSION}

This study found that some noise levels during the Zumba Fitness sessions done at this particular studio exceeded the maximum allowable level of $115 \mathrm{dBA}$ even though the total weighted-average did not exceed the allowable $85 \mathrm{dBA}$ level. This is a pertinent fact that needs to be disseminated and communicated to the Zumba Fitness regulars; for despite its many health benefits, Zumba fitness with its accompanying loud music has the potential to harm the hearing as prolonged exposure to this level has been proven to causing hearing loss. Future research should focus on cohort studies documenting hearing levels of participants before and after joining Zumba classes while controlling for other causes of sensorineural hearing loss.

\section{ACKNOWLEDGEMENT}

We would like to thank Zumba Kuantan and Try My Gym for accommodating this study, and Ear and 
Hearing Clinic, Kulliyyah of Medicine, IIUM for the assistance rendered.

\section{REFERENCES}

1. Kapoor N. Noise, the silent killer. In: Singh SB et al., editors. Translational Research in Environmental and Occupational Stress. India: Springer; 2014. p. 155-167.

2. Rampal KG, Ailin R, Noor HI. Auditory disorders. In: Textbook of Occupational Medical Practices. 3rd ed. Singapore: World Scientific Publication; 2011. P. 295-329.

3. Norazimah CA, Badrul B. Noise-induced hearing loss (NIHL): An ignorant workplace hazard. J Global Business Econ. 2014; 9(1): 18-32.

4. Tung CY, Chao KP. Effect of recreational noise exposure on hearing impairment among teenage students. Res Dev Disabil. 2013; 34: 126-132.

5. Sulaiman AH, Seluakumaran K, Husain R. Hearing risk associated with the usage of personal listening devices among urban high school students in Malaysia. Public Health. 2013; 127: 710-715.

6. Vogel I, Brug J, van der Ploeg CPB, Raat H. Young people: taking few precautions against hearing loss in discotheques. J Adolescent Health. 2010; 46: 499-502.

7. Zhao F, Manchaiah VKC, French D, Price SM. Music exposure and hearing disorders: An overview. Int J Audiol. 2010; 49: 56-64.

8. Ljubojević A, Jakovljević $\mathrm{V}$, Popržen M. Effects of Zumba fitness program on body composition of women. SportLogia. 2014; 10(1): 29-33.

9. Yuen M. Khairy: Government targets half of Malaysians to be active exercisers in five years. The Star. 2014 Sept 7: Sect. Nation.

10. Okonkwo NM. Energy expenditure and physiological responses to 60 minute Zumba aerobic sessions (group class versus home) in healthy adult females. [Unpublished master's thesis]. United Kingdom: University of Chester; 2012.

11. Ministry of Human Resources. Factories and Machinery (Noise Exposure) Regulations 1989. In: Laws of Malaysia Factories and Machinery Act with Regulations, 18th ed. Kuala Lumpur: MDC Publishers Sdn Bhd; 2007. p. 411-425.

12. Park MY. Assessment of potential noise-induced hearing loss with commercial Karaoke noise. Int
$J$ Ind Ergonom. 2003; 31(6): 375-385.

13. Chepesiuk R. Decibel hell: The effects of living in a noisy world. Environ Health Perspect. 2005; 113(1): A34A41.

14. Juman S, Karmody CS, Simeon D. 2003. Hearing loss in steelband musicians. Otolaryngol Head Neck Surg. 2003; 131: 461-465.

15. Rabinowitz PM. The public health significance of noise-induced hearing loss. In: Le Prell CG, Henderson D, Fay RR, Popper AN, editors. Noise-induced hearing loss: Scientific advances. New York: Springer Science + Business Media; 2012. p. 13-25.

16. Vogel I, van der Ploeg CPB, Brug J, Raat H. Music venues and hearing loss: Opportunities for and barriers to improving environmental conditions. Int J Audiol. 2009; 48: 531-536.

17. Widen SE, Holmes AE, Johnson $T$, Bohlin M, Erlandsson SI. Hearing, use of hearing protection, and attitudes towards noise among young American adults. Int J Audiol. 2009; 48: 537-545. 